Investigation of a scanned cylindrical ultrasound system for breast hyperthermia

This article has been downloaded from IOPscience. Please scroll down to see the full text article.

2006 Phys. Med. Biol. 51539

(http://iopscience.iop.org/0031-9155/51/3/005)

The Table of Contents and more related content is available

Download details:

IP Address: 140.112.113.225

The article was downloaded on 06/01/2009 at 06:08

Please note that terms and conditions apply. 


\title{
Investigation of a scanned cylindrical ultrasound system for breast hyperthermia
}

\author{
Kuen-Cheng $\mathrm{Ju}^{1}$, Li-Te Tseng ${ }^{1}$, Yung-Yaw Chen ${ }^{2}$ and Win-Li Lin ${ }^{1,3}$ \\ ${ }^{1}$ Institute of Biomedical Engineering, National Taiwan University, Taipei, Taiwan \\ 2 Department of Electrical Engineering, National Taiwan University, Taipei, Taiwan \\ ${ }^{3}$ Division of Medical Engineering Research, National Health Research Institutes, Miaoli, Taiwan \\ E-mail: winli@ntu.edu.tw
}

Received 3 June 2005, in final form 2 November 2005

Published 11 January 2006

Online at stacks.iop.org/PMB/51/539

\begin{abstract}
This paper investigates the feasibility of a scanned cylindrical ultrasound system for producing uniform heating from the central to the superficial portions of the breast or localized heating within the breast at a specific location. The proposed system consists of plane ultrasound transducer(s) mounted on a scanned cylindrical support. The breast was immersed in water and surrounded by this system during the treatment. The control parameters considered are the size of the transducer, the ultrasound frequency, the scan angle and the shifting distance between the axes of the breast and the system. Three-dimensional acoustical and thermal models were used to calculate the temperature distribution. Non-perfused phantom experiments were performed to verify the simulation results. Simulation results indicate that high frequency ultrasound could be used for the superficial heating, and the scan angle of the transducer could be varied to obtain an appropriate high temperature region to cover the desired treatment region. Low frequency ultrasound could be used for deep heating and the high temperature region could be moved by shifting the system. In addition, a combination of low and high frequency ultrasound could result in a portion treatment from the central to the superficial breast or an entire breast treatment. Good agreement was obtained between non-perfused experiments and simulation results. The findings of this study can be used to determine the effects of the control parameters of this system, as well as to select the optimal parameters for a specific treatment.
\end{abstract}

\section{Introduction}

Hyperthermia is the process of heating tissues to a therapeutic temperature to kill cancerous cells and damage tumour tissues. Numerous investigations (Overgaard 1989, Bornstein et al 1993, van der Zee et al 2000) indicate that it can also act as an auxiliary 
therapy to radiotherapy, chemotherapy, etc due to its significant enhancing effects to these therapies. Due to the physical properties of ultrasound, it is suitable for heating both deep and shallow tissues. The breast is particularly well suited for ultrasound hyperthermia owing to the low blood perfusion and the absence of bones and large blood vessels. In addition, the convex shape of breast provides a sufficient acoustical window for delivering ultrasound energy.

Lu et al (1996) developed a hyperthermia treatment system with a cylindrical transducer array applicator mounted on a three-dimensional translation table. The system consists of 384 ultrasound transducers mounted on the inner surface of a $25 \mathrm{~cm}$ diameter cylinder. The ultrasound transducers are 2.5 MHz for the low frequency and 4.0-4.5 MHz for the high frequency. The simulation results demonstrate that a combination of low and high frequencies can deliver appropriate power deposition to achieve and maintain uniform temperature distribution for a target area ranging from a single quadrant to a whole breast. Malinen et al (2004) performed a simulation study to investigate a hemispherical phase array applicator for breast tumour. The applicator consists of 191 elements, and its geometrical focus is mechanically placed in the middle of the tumour region. The focus is then electrically scanned to cover the entire tumour region. Simulation results show the feasibility to produce localized heating with the tumour diameter from 1.5 to $2.4 \mathrm{~cm}$, depending on the tumour position. Although simulation results of these systems show their ability to produce localized or uniform heating of the breast, hardware requirements of hundreds of ultrasound transducers make these systems become complex and hard to implement.

In this study, we utilized a simulation study to investigate the feasibility of a scanned cylindrical ultrasound system to produce localized heating within the breast or uniform heating from the central to the superficial region of the breast. Three-dimensional (3D) ultrasound field and thermal models were developed to simulate the temperature distribution produced by this system. For the proposed system, ultrasound transducer(s) were mounted on a scanned cylindrical supporter to form a breast heating system. The parameters investigated, which might influence the temperature distribution, are the size of the transducer, the ultrasound frequency, the shifting distance of the system and the scan angle of the transducer. The effects of blood perfusion and the temperature of cooling water on the treatable domain were also studied. Non-perfused phantom experiments were also performed to verify the simulation results.

\section{Methods}

\subsection{System configuration}

The geometry of the cylindrical ultrasound heating system is shown in figure 1(a). Ultrasound power is emitted from the scanning transducer, and the breast is taken as a hemisphere with a diameter of $12 \mathrm{~cm}$. The centre of the ultrasound transducer(s) was arranged on the scanned cylindrical supporter at a depth of $Z \mathrm{~cm}$. As shown in figure 1(b), the geometric centre of the system can be moved to a specific location within the breast by shifting the system a distance $(D)$ away from the central axis of the breast. Furthermore, the transducer can be scanned back and forth at an angle of $\varphi$. The factors potentially influencing the ultrasound power deposition within the breast are the size of the transducer, the ultrasound frequency $(f)$, the scan angle $(\varphi)$, as well as the shifting distance $(D)$ between the central axes of the breast and the system. 

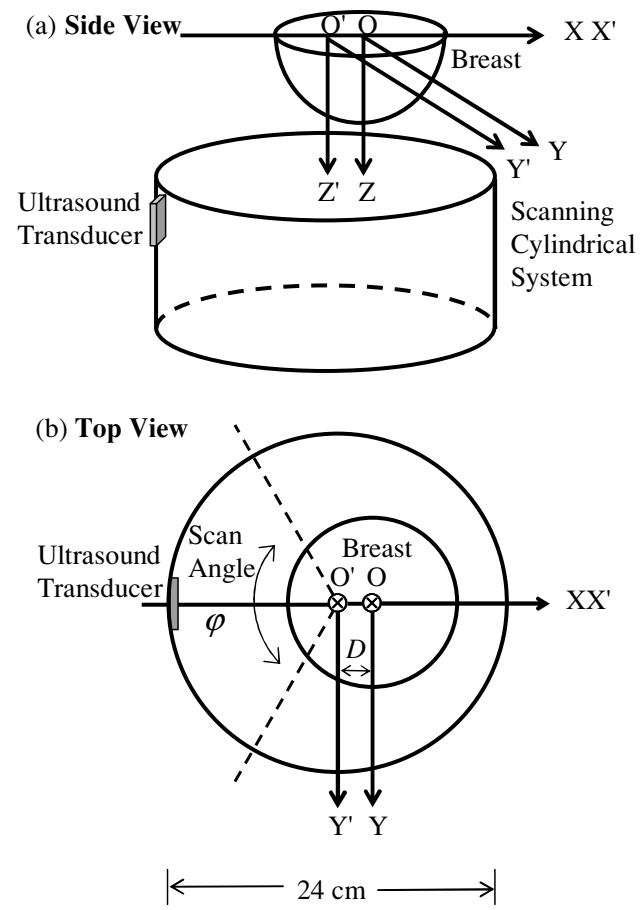

Figure 1. (a) Schematic diagram of the geometry studied for the heating patterns within a breast when a scanned cylindrical ultrasound system is used for hyperthermia treatment. An ultrasound transducer is mounted on the scanned cylindrical system at a depth of $Z \mathrm{~cm}$. The breast is assumed to be a $12 \mathrm{~cm}$ diameter hemisphere. (b) Relative positions of the heating system and the breast. The central axis of the ultrasound system is shifted a distance of $D \mathrm{~cm}$ away from that of the breast along the $X$-axis. The transducer scans back and forth with respect to the $Z^{\prime}$-axis with a scan angle $(\varphi)$.

\subsection{Acoustic model}

Two separate steps were used to calculate the power deposition within the breast. First, the ultrasound power deposition of a stationary transducer was calculated, and then this power deposition was appropriately rotated to calculate the accumulation effect of the scanning transducer around the breast. The acoustic model was a simple water-tissue model. Assuming the density and the speed of sound in the two layers are close, the reflection and refraction at the water-tissue interface can be ignored (Lu et al 1998). To simulate the ultrasound power deposition for a stationary transducer, an efficient and accurate numerical method (Ocheltree and Frizzell 1989) was employed to calculate the acoustic field in a homogeneous medium. In this model, the plane source is divided into small elements, and sums the contributions to the pressure at a point from all elements. The size of each small element must be small enough to satisfy the assumption of this model. In this study, an element size of $0.5 \mathrm{~mm}$ was used to fit the requirement. Parameters used in our simulation are listed in table 1 (Foster and Hunt 1979, Bowman 1982, Skinner et al 1998).

The absorbed power density can be obtained from

$$
q=\frac{\alpha|p|^{2}}{\rho c}
$$

where $\alpha$ is the ultrasound absorption coefficient of tissue, $\rho$ is the tissue density, $c$ is the speed 
Table 1. Parameters used in acoustic and thermal calculations.

\begin{tabular}{ll}
\hline Tissue parameter & Value \\
\hline Speed of sound, $c$ & $1500 \mathrm{~m} \mathrm{~s}^{-1}$ \\
Tissue density, $\rho$ & $1000 \mathrm{~kg} \mathrm{~m}^{-3}$ \\
Ultrasound absorption coefficient, $\alpha$ & $8.6 f^{1.5} \mathrm{~Np} \mathrm{~m}^{-1 \mathrm{a}}$ \\
Thermal conductivity, $k$ & $0.5 \mathrm{~W} \mathrm{~m}^{-1}{ }^{\circ} \mathrm{C}^{-1}$ \\
Specific heat (blood), $c_{\mathrm{b}}$ & $3550 \mathrm{~J} \mathrm{~kg}^{-1}{ }^{\circ} \mathrm{C}^{-1}$ \\
Blood perfusion, $W$ & $0.5,1.5,3.5 \mathrm{~kg} \mathrm{~m}^{-3} \mathrm{~s}^{-1}$ \\
\hline
\end{tabular}

${ }^{\mathrm{a}} f$ in MHz.

of sound. In this study, the absorption coefficient was set to be the same as the attenuation coefficient of the ultrasound within the breast, assuming that the attenuated power is absorbed locally. A constant absorption coefficient throughout the breast was also assumed. To reduce the number of calculations, only the voxel within the breast was calculated. A voxel size of $2 \times 2 \times 2 \mathrm{~mm}^{3}$ was used.

In this system, the transducer is continuously scanned back and forth. To account for the scanning, the stationary power deposition for the plane transducer was rotated $5^{\circ}$ with respect to the central axis step by step until it covered the predetermined scan angle. We assumed that the scanning speed was fast enough, and employed an averaged method to approximate the power deposition produced by the scanning transducer (Ebbini and Cain 1991). Dividing the scan angle into $N$ steps, the average absorbed power density $Q$ can be obtained from

$$
Q=\frac{1}{N} \sum_{i=1}^{N} q_{i},
$$

where $q_{i}$ is the absorbed power density associated with the stationary transducer at the angle of the $i$ th step and $N$ is equivalent to the scan angle divided by $5^{\circ}$.

\subsection{Thermal model}

To solve for the temperature distribution, Pennes' bioheat transfer equation (BHTE) (Pennes 1948) is used:

$$
\rho c_{\mathrm{t}} \frac{\partial T}{\partial t}=k \nabla^{2} T-W c_{\mathrm{b}}\left(T-T_{\mathrm{ar}}\right)+Q,
$$

where $k$ is the thermal conductivity of the breast tissue; $W$ is the blood perfusion; $c_{\mathrm{t}}$ and $c_{\mathrm{b}}$ are the specific heat of tissue and blood, respectively, and $T_{\mathrm{ar}}$ is the arterial temperature $\left(37^{\circ} \mathrm{C}\right)$. In a scanning system, the temperature at a location rises and falls periodically. Moros et al (1988) reported that the temporal temperature fluctuation is small when blood perfusion is low and scanning speed is high. We assume that the scanning speed is fast enough; hence the temperature fluctuation can be neglected. Therefore, the steady-state BHTE can be applied:

$$
k \nabla^{2} T-W c_{\mathrm{b}}\left(T-T_{\mathrm{ar}}\right)+Q=0 .
$$

The averaged absorbed ultrasound power density $Q$ was obtained from equation (2) for a given output power level. The anatomic properties were assumed to remain constant throughout the entire field, and metabolism was neglected due to its small contribution to the temperature changes (Roemer 1990). A constant and uniform distributed blood perfusion of $1.5 \mathrm{~kg} \mathrm{~m}^{-3} \mathrm{~s}^{-1}$ (Lu et al 1996) was assumed in this study; two extreme values $\left(0.5\right.$ and $\left.3.5 \mathrm{~kg} \mathrm{~m}^{-3} \mathrm{~s}^{-1}\right)$ were also examined in some cases. The cooling water surrounding the breast was set to be $37^{\circ} \mathrm{C}$; 


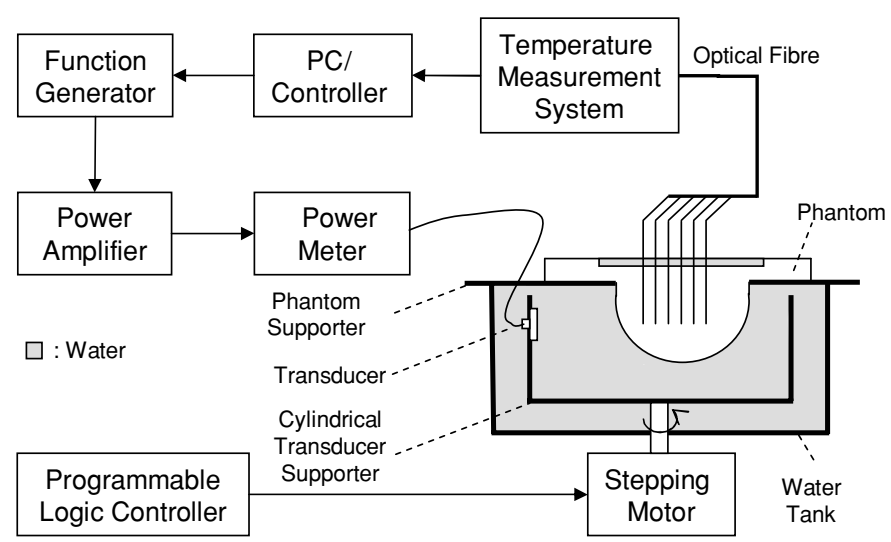

Figure 2. Block diagram of the experimental set-up.

a higher water temperature of $41^{\circ} \mathrm{C}$ was examined in some cases. For the water-tissue boundary, it was assumed that the voxel in the breast adjacent to water is kept at the water temperature ( $\mathrm{Lu}$ et al 1996). For comparison, the output power of the transducer was tuned to have a maximum temperature of $45^{\circ} \mathrm{C}$ within the breast unless mentioned. Temperatures greater than $45^{\circ} \mathrm{C}$ cannot be tolerated by patients (Kumaradas and Sherar 2003).

The BHTE was solved by using a numerical finite difference method. The simulation code was developed in-house and the accuracy has been previously verified (Liu et al 2004) by comparing with the published experimental and simulated data (Daum and Hynynen 1999).

\subsection{Experimental set-up}

The block diagram of the in vitro experimental set up is shown in figure 2 . A $3 \times 3 \mathrm{~cm}^{2}$ ultrasound transducer with resonant and harmonic frequencies of 1.08 and $3.42 \mathrm{MHz}$, respectively, was mounted on a $24 \mathrm{~cm}$ diameter cylindrical supporter. The supporter was connected to a PLC (programmable logic controller) controlled stepping motor to perform the scanning motion. Predetermined scanning speed and scan angle could be set in the PLC. In this study a constant scanning speed of $5 \mathrm{~s}$ per circle was used. All of the system was immerged in a tank of degassed, distilled water with a temperature of $25{ }^{\circ} \mathrm{C}$. The driving signal of the ultrasound transducer is supplied by a power amplifier (100A250A, Amplifier Research, PA, USA), which is driven by a function generator (33120A, Agilent, USA). The electrical power was measured by using a power meter (4421, Bird, OH, USA) at the amplifier output. The function generator can be dynamically adjusted to control the amplitude and frequency of the driving signal. A silica-based optical fibre temperature measurement system (FISO, Canada) was used to monitor the temperature elevations. Experimental data (Hynynen and Edwards 1989) indicate that fused silica probes appear to have a small viscous heating artefact in plane-wave hyperthermia. Hence, the effect of heating artefact of the fibre sensor was ignored. A fuzzy logic controller was employed to give a fast rise time during the heating process. The target was to heat the breast to have a maximum temperature of $34{ }^{\circ} \mathrm{C}$. Without the controller, it took a long time to approach a steady state. The phantom was made from water-based pharmaceutical gels, graphite powder and n-propanol (Madsen et al 1978). The final sample was evaluated by a pulser-receiver system (5800, Panametric, MA, USA) before experimentation. The measured sound speed and attenuation coefficient of the phantom are $1521 \mathrm{~m} \mathrm{~s}^{-1}$ and $7.4 \mathrm{~Np} \mathrm{~m}^{-1}$ at $1 \mathrm{MHz}$, respectively. 

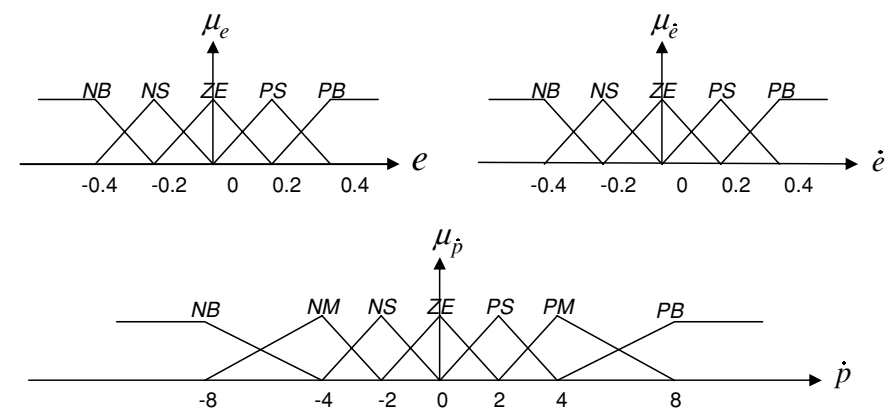

Figure 3. The input and output membership functions of the fuzzy sets for the fuzzy logic controller. The fuzzy set NB means negative big; NM-negative medium; NS—negative small; ZE—zero; PS—positive small; $\mathrm{PM}$ - positive medium and $\mathrm{PB}$ - positive big.

Table 2. The rule base for the fuzzy logic controller.

\begin{tabular}{llllll}
\hline$\dot{e}:$ & NB & NS & ZE & PS & PB \\
\hline$e$ & & & $\dot{p}$ & & \\
\cline { 2 - 5 } NB & NB & NB & NM & NS & ZE \\
NS & NB & NM & NS & ZE & PS \\
ZE & NM & NS & ZE & PS & PM \\
PS & NS & ZE & PS & PM & PB \\
PB & ZE & PS & PM & PB & PB \\
\hline
\end{tabular}

\subsection{Fuzzy logic controller}

In this study, a fuzzy logic controller (Chen et al 1999) was used in phantom experiments and transient simulations. The controller is employed to determine the power level for the heating system. The reference temperature $\left(T_{\mathrm{r}}\right)$ is the target of control temperature $\left(T_{\mathrm{c}}\right)$ at a specific control point. The temperature error $\left(e=T_{\mathrm{r}}-T_{\mathrm{c}}\right)$ at the control point as well as the change-in-error $(\dot{e})$ are regarded as the input variables, while the change of the output power $(\dot{p})$ is taken as the output variable. The fuzzy logic rule is

$$
R_{i}: \quad \text { if } \dot{e} \text { is } A_{i} \quad \text { and } \quad e \text { is } B_{i} \text { then } \dot{p} \text { is } C_{i} .
$$

The membership functions for the input and output shown in figure 3 and table 2 are used as the control rule base. These if-then rules are deduced from 'expert's experience'. For example, when $e$ is $\mathrm{PB}$ (positive big, $T_{\mathrm{r}}$ is much higher than $T_{\mathrm{c}}$ ) and $\dot{e}$ is still PS (positive small, heating rate is slow), a positive big (PB) increment $(\dot{p})$ adding to the output power is employed to speed up the heating.

\section{Results}

\subsection{Verification of the model}

In vitro experimentations were used to verify the simulation results. Figure 4 is the comparison between the simulations (solid line) and the experimental results ( $*$ ) for a $3 \times 3 \mathrm{~cm}^{2}$ transducer at $Z=3 \mathrm{~cm}$ with a $360^{\circ}$ scan angle. Measurement points, $1 \mathrm{~cm}$ apart for each, were arranged in a line passing through the central axis of the breast at the transducer's depth $(Z=3 \mathrm{~cm})$. Non-perfused simulations were performed to compare with the phantom experiments. All 


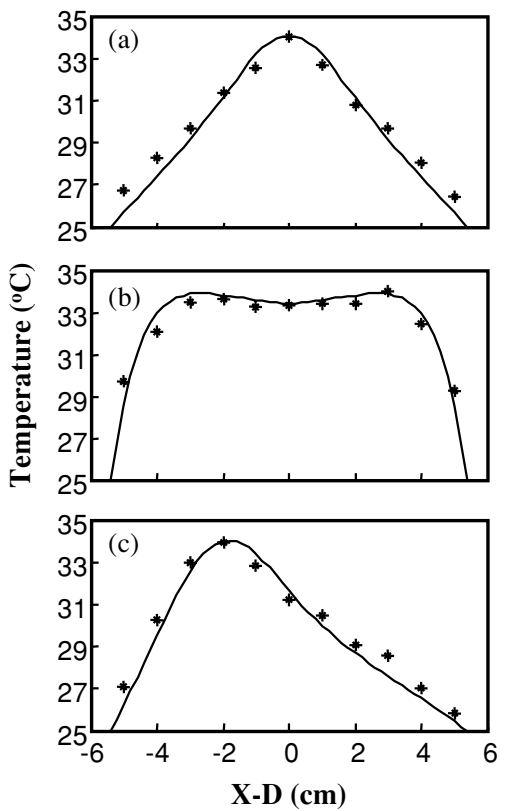

Figure 4. Non-perfused experimental results (indicated by $*$ ) compared with the simulation (denoted by solid lines) for a $3 \times 3 \mathrm{~cm}^{2}$ transducer located at $Z=3 \mathrm{~cm}$, with a scan angle of $\varphi=$ $360^{\circ}$; (a) and (b) for a shifting distance $D=0$, and ultrasound frequencies of 1.08 and $3.42 \mathrm{MHz}$, respectively; and (c) for $D=2 \mathrm{~cm}$ and a $1.08 \mathrm{MHz}$ frequency.

parameters for these simulations were in accord with the phantom material, e.g. the acoustic speed and the attenuation coefficient, and the driving frequency of the ultrasound transducer. The geometrical centre of the system was selected as a control point, and the reference temperature $\left(T_{\mathrm{r}}\right)$ at the control point was obtained from the simulation result. By using the fuzzy logic controller, the temperature at the control point $\left(T_{\mathrm{c}}\right)$ could be maintained at the reference temperature after the steady state was reached. Figures 4(a) and (b) are for driving frequencies of 1.08 and $3.42 \mathrm{MHz}$ with zero shifting distance, respectively. Figure 4(c) is for $1.08 \mathrm{MHz}$ with a $2 \mathrm{~cm}$ shifting distance. These results show the agreement between the theoretical calculations and the experimental results for a non-perfused case. Owing to the absence of blood perfusion in the simulation and experimentation, figure 4(b) shows that not only the superficial region but also the central region of the breast was heated, even though a high frequency of $3.42 \mathrm{MHz}$ was used.

\subsection{Effects of control parameters}

The size of the transducer and the ultrasound frequency are parameters potentially affecting the temperature distribution of the breast. To examine the effects of these parameters on the temperature distribution within the breast when the proposed system is used, the size of the transducer varies from $3 \times 2$ to $3 \times 4 \mathrm{~cm}^{2}$, and the frequency from 1.08 to $3.42 \mathrm{MHz}$. Figure 5 shows the temperature distributions for different transducer sizes and ultrasound frequencies when the scan angle is $360^{\circ}$ and the shifting distance is $0 \mathrm{~cm}$. Figures 5(a)-(c) are for $3 \times 2,3 \times 3$ and $3 \times 4 \mathrm{~cm}^{2}$ transducers, respectively, located at $Z=3 \mathrm{~cm}$ with a $1.08 \mathrm{MHz}$ driving frequency. Figures 5(d)-(f) are for 3.42 MHz. Owing to the central axis of the system being coincident with that of the breast, the temperature within the breast is symmetrical to 


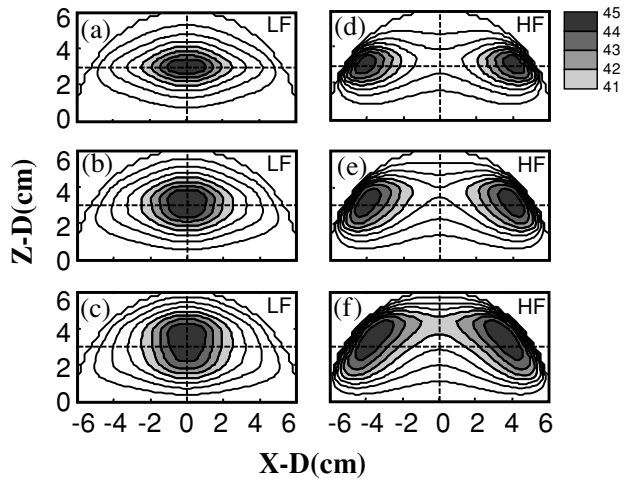

Figure 5. Temperature distributions for a $360^{\circ}$ scan angle, a $0 \mathrm{~cm}$ shifting distance and the transducer located at $Z=3 \mathrm{~cm}$; (a) to (c) are results for a $1.08 \mathrm{MHz}$ transducer with sizes of $3 \times 2 \mathrm{~cm}^{2}, 3 \times 3 \mathrm{~cm}^{2}$ and $3 \times 4 \mathrm{~cm}^{2}$, respectively; (d) to (f) are results for a $3.42 \mathrm{MHz}$ transducer. The horizontal and vertical dashed lines indicate the transducer depth and the central axis of the system, respectively. The shaded area represents the region with a temperature higher than $41^{\circ} \mathrm{C}$, and each contour increases by $1^{\circ} \mathrm{C}$. HF denotes high frequency, $3.42 \mathrm{MHz}$; LF denotes low frequency, $1.08 \mathrm{MHz}$.

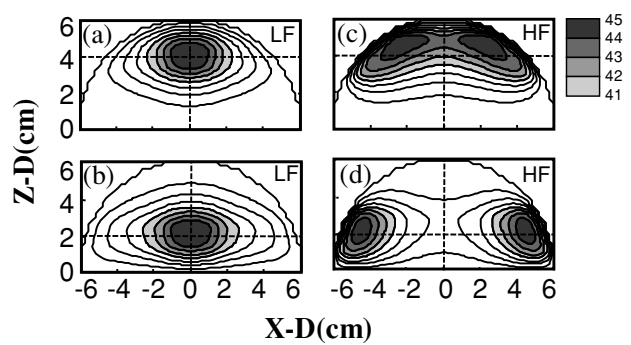

Figure 6. Temperature distributions for a $3 \times 3 \mathrm{~cm}^{2}$ transducer, $360^{\circ}$ scan angle and $0 \mathrm{~cm}$ shifting distance; (a) and (b) are results for an ultrasound frequency of $1.08 \mathrm{MHz}$, with the transducer at $Z=4 \mathrm{~cm}$ and $2 \mathrm{~cm}$, respectively; (c) and (d) are results for an ultrasound frequency of $3.42 \mathrm{MHz}$.

the central axis. To simplify the presentation, only a sagittal view passing through the centre of the breast is shown. Figures 5(a)-(c) show that when a $1.08 \mathrm{MHz}$ transducer is used, the high temperature region is at the centre of the breast and its size increases with the size of the transducer. For the case with high frequency ultrasound (figures 5(d)-(f)), the superficial region of the breast is heated. In the following simulations, a $3 \times 3 \mathrm{~cm}^{2}$ transducer would be employed.

Figure 6 shows the simulation results for a $3 \times 3 \mathrm{~cm}^{2}$ transducer at various depths with a $360^{\circ}$ scan angle and zero shifting distance $(D=0)$. Figures $6(\mathrm{a})$ and (b) are the temperature distributions for a $1.08 \mathrm{MHz}$ transducer located at $Z=4$ and $2 \mathrm{~cm}$, respectively, and figures 6(c) and (d) are for $3.42 \mathrm{MHz}$, respectively. It demonstrates that the position of the high temperature region changes with the position of the transducer.

As the central axis of the scanned cylindrical system is shifted, a distance of $D \mathrm{~cm}$ away from that of the breast, the temperature distribution within the breast becomes asymmetric to the breast's central axis. Figure 7 shows the simulation results when a $3 \times 3 \mathrm{~cm}^{2}$ transducer and a $360^{\circ}$ scan angle are employed. Figures 7 (a) and (b) are results for $1.08 \mathrm{MHz}$ driving frequency, and figures $7(\mathrm{c})$ and (d) are for $3.42 \mathrm{MHz}$. In figures 7(a) and (c), the transducer is 

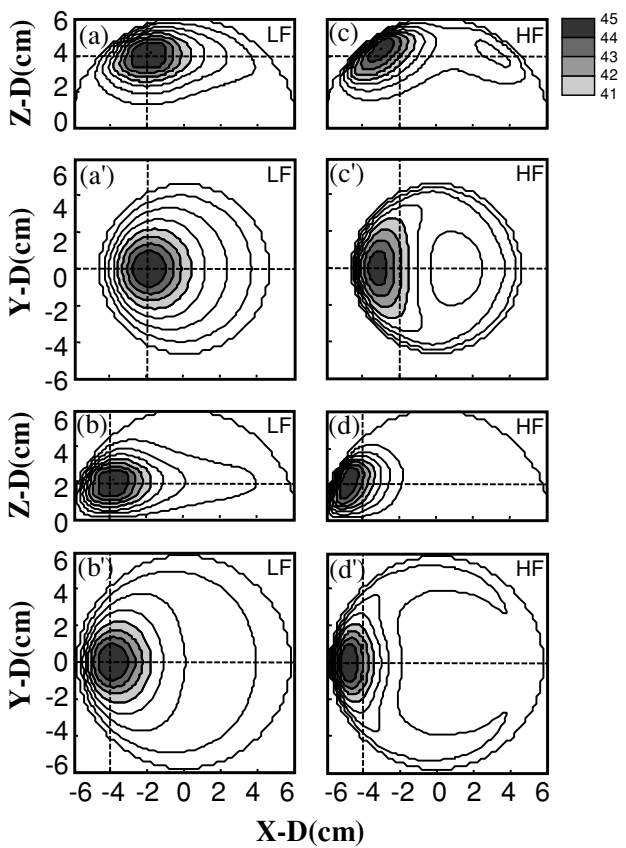

Figure 7. Temperature distributions for a $3 \times 3 \mathrm{~cm}^{2}$ transducer, $360^{\circ}$ scan angle; (a) and (c) are results for transducer at $Z=4 \mathrm{~cm}$ and shifting distance $D=2 \mathrm{~cm}$, with the frequencies of 1.08 and $3.42 \mathrm{MHz}$, respectively; (b) and (d) are results for $Z=2 \mathrm{~cm}$ and $D=4 \mathrm{~cm}$, with the frequencies of 1.08 and $3.42 \mathrm{MHz}$, respectively. $\left(\mathrm{a}^{\prime}-\mathrm{d}^{\prime}\right)$ are the temperature distributions on the $X-Y$ plane at the transducer depth.

located at $Z=4 \mathrm{~cm}$ and a shifting distance of $2 \mathrm{~cm}$. Figures 7(b) and (d) are for a transducer position at $Z=2 \mathrm{~cm}$ with a shifting distance of $4 \mathrm{~cm}$. Figures $7\left(\mathrm{a}^{\prime}\right)-\left(\mathrm{d}^{\prime}\right)$ are the temperature distributions on the $X-Y$ plane at the transducer's depth corresponding to figures 7(a)-(d). Figure 7 reveals that when a $1.08 \mathrm{MHz}$ transducer is used, the high temperature region is shifted with the shifting distance for all cases. As a $3.42 \mathrm{MHz}$ transducer is used, the location of the high temperature region changes dramatically with the shifting distance. The temperature of the central portion of the breast still maintains a low level, while the high temperature region converges from the superficial region of the entire breast to a small region in the left breast when the system shifts.

In addition to the ultrasound frequency and the shifting distance of the system, the scan angle $(\varphi)$ of the transducer can also be employed to control the heating pattern. To examine the effects of the scan angle on the temperature distribution, the scan angle is varied from $120^{\circ}$ (figures $8(\mathrm{a})-(\mathrm{c})$ ) to $240^{\circ}$ (figures $8(\mathrm{~d})-(\mathrm{f})$ ) when a $3 \times 3 \mathrm{~cm}^{2}$ transducer at $Z=3 \mathrm{~cm}$ is used, with a shifting distance of $0 \mathrm{~cm}$. Figures 8 (a) and (d) show the heating pattern of the breast for a $1.08 \mathrm{MHz}$ frequency; figures 8(b) and (e) are for $3.42 \mathrm{MHz}$ and figures $8(\mathrm{c})$ and (f) show results for the combination of 1.08 and $3.42 \mathrm{MHz}$ frequencies with 1:1 or 3:4 power weightings, respectively. Figures $8\left(\mathrm{a}^{\prime}\right)-\left(\mathrm{f}^{\prime}\right)$ are the temperature distributions on the $X-Y$ plane at the transducer's depth corresponding to figures 8(a)-(f). This simulation reveals that as the scan angle varies, the heating pattern is changed. Figures $8(a)$ and (d) indicate that when a $1.08 \mathrm{MHz}$ transducer is used, the high temperature region is located in the central portion of the breast and its shape varies with the scan angle. Figure $8\left(\mathrm{a}^{\prime}\right)$ reveals that the left portion of the breast facing the transducer has a higher temperature rise. Figure $8\left(\mathrm{~d}^{\prime}\right)$, with a scan 

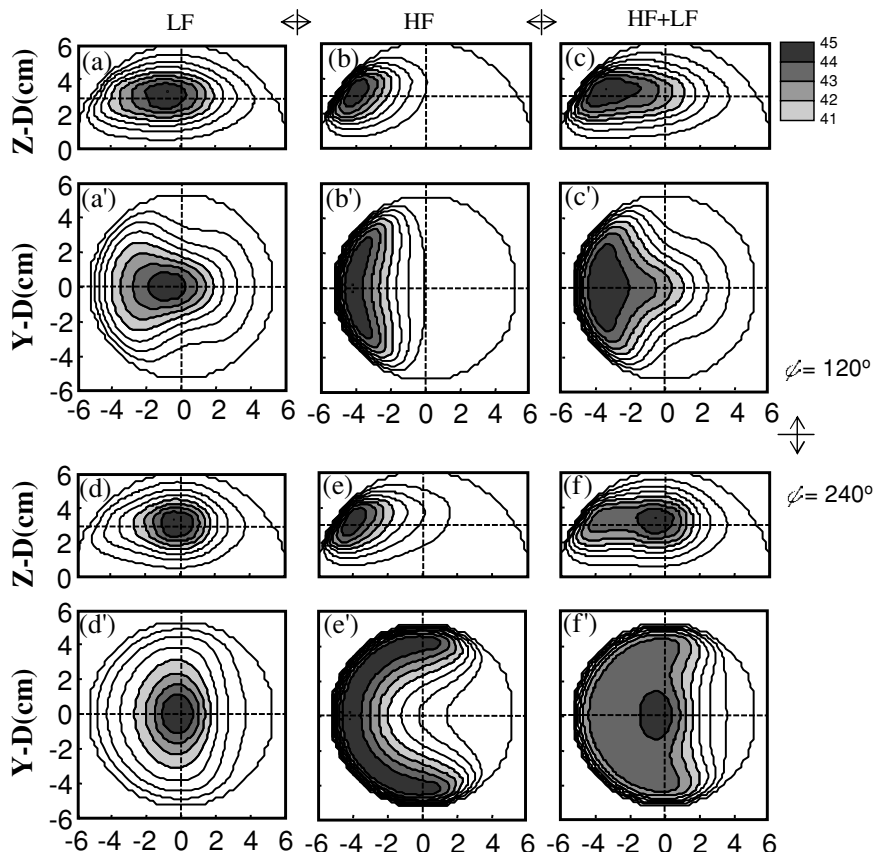

$\mathrm{X}-\mathrm{D}(\mathrm{cm})$

Figure 8. Temperature distributions for a $3 \times 3 \mathrm{~cm}^{2}$ transducer at $Z=3 \mathrm{~cm}$, and shifting distance $D=0 \mathrm{~cm}$; (a)-(c) are results for a scan angle of $120^{\circ}$ with ultrasound frequencies of $1.08 \mathrm{MHz}$, $3.42 \mathrm{MHz}$ and the combination of 1.08 and $3.42 \mathrm{MHz}$ (with a power weighting of 1:1), respectively; (d)-(f) are results for a scan angle of $240^{\circ}$ with ultrasound frequencies of $1.08 \mathrm{MHz}, 3.42 \mathrm{MHz}$, and the combination of 1.08 and $3.42 \mathrm{MHz}$ (with a power weighting of 3:4), respectively; $\left(\mathrm{a}^{\prime}\right)-\left(\mathrm{f}^{\prime}\right)$ are the temperature distributions on the $X-Y$ plane at the transducer's depth.

angle of $240^{\circ}$, displays a distinct heating pattern from that of a $120^{\circ}$ scan angle simulation. Figures $8\left(b^{\prime}\right)$ and $\left(e^{\prime}\right)$, for a $3.42 \mathrm{MHz}$ frequency, indicate that the domain with high temperature is always located in the superficial portion of the breast and its size is proportional to the scan angle. Figures $8\left(\mathrm{c}^{\prime}\right)$ and $\left(\mathrm{f}^{\prime}\right)$ show that by combining $1.08 \mathrm{MHz}$ and $3.42 \mathrm{MHz}$ frequencies with appropriate power weightings, the temperature rise within the scanned region is a pretty uniform plateau from the surface to the central portion of the breast.

\subsection{Blood perfusion and cooling temperature}

Figures 8 (c) and (f) show the possibility of producing heating patterns from the central to the superficial portion of the breast by combining high and low frequency ultrasound. Blood perfusion and the cooling water temperature may affect the temperature distribution of the breast. To examine the effect of cooling water temperature on the temperature distribution of the breast, the temperature for cooling water was set to be $41{ }^{\circ} \mathrm{C}$. Figures 9 (a)-(c) are the temperature distributions corresponding to the transducer located at $Z=4 \mathrm{~cm}, 3 \mathrm{~cm}$ and $2 \mathrm{~cm}$, respectively, all with a combination of 1.08 and $3.42 \mathrm{MHz}$ ultrasound frequencies at a properly selected power weighting of $3: 4$, for a $3 \times 3 \mathrm{~cm}^{2}$ transducer, a $240^{\circ}$ scan angle, zero shifting distance and $1.5 \mathrm{~kg} \mathrm{~m}^{-3} \mathrm{~s}^{-1}$ blood perfusion. Figures 9(d)-(f) examine the effect of blood perfusion: a $3 \times 3 \mathrm{~cm}^{2}$ transducer located at $Z=3 \mathrm{~cm}$ with a $360^{\circ}$ scan angle and zero shifting distance, while blood perfusion is $0.5,1.5$ and $3.5 \mathrm{~kg} \mathrm{~m}^{-3} \mathrm{~s}^{-1}$, respectively. For 

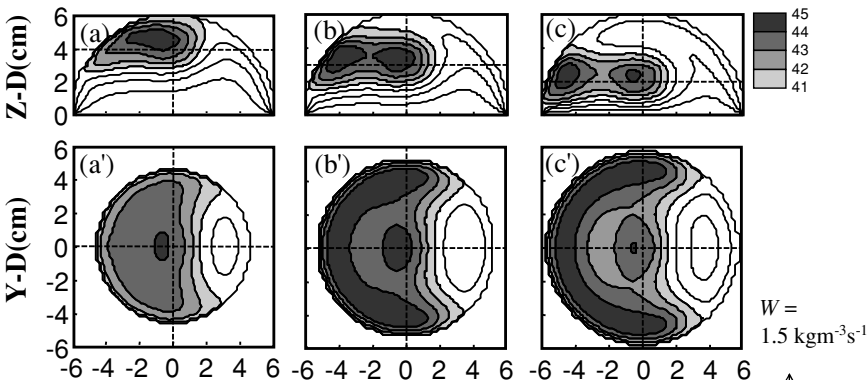

$W=0.5$

$W=1.5$
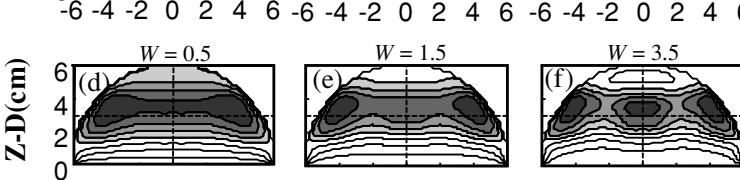
个
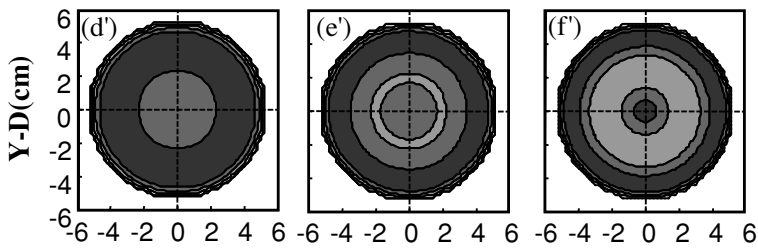

$\mathrm{X}-\mathrm{D}(\mathrm{cm})$

Figure 9. Temperature distributions for a $3 \times 3 \mathrm{~cm}^{2}$ transducer, $0 \mathrm{~cm}$ shifting distance, a combination of $1.08 \mathrm{MHz}$ and $3.42 \mathrm{MHz}$ frequencies and a cooling water temperature of $41{ }^{\circ} \mathrm{C}$. (a)-(c) are results for a scan angle of $240^{\circ}$, a uniform perfusion of $1.5 \mathrm{~kg} \mathrm{~m}^{-3} \mathrm{~s}^{-1}$ for the entire breast, a power weighting of 3:4, with the transducer located at $Z=4,3$ and $2 \mathrm{~cm}$, respectively; (d)-(f) are results for the transducer at $Z=3 \mathrm{~cm}$, a scan angle of $360^{\circ}$, the combination of $1.08 \mathrm{MHz}$ and $3.42 \mathrm{MHz}$ with a power weighting 1:5, 1:3 and 1:2 for perfusions of $0.5,1.5$ and $3.5 \mathrm{~kg} \mathrm{~m}^{-3} \mathrm{~s}^{-1}$, respectively. $\left(\mathrm{a}^{\prime}\right)-\left(\mathrm{f}^{\prime}\right)$ are the temperature distributions on the $X-Y$ planes at the transducer's depth corresponding to (a)-(f).

the purpose of uniform heating from the central portion to the superficial region of the breast, the power weightings of 1.08 and $3.42 \mathrm{MHz}$ were properly selected as 1:5, 1:3 and 1:2 for figures $9(\mathrm{~d})-(\mathrm{f})$, respectively. Figures $9\left(\mathrm{a}^{\prime}\right)-\left(\mathrm{f}^{\prime}\right)$ are the temperature distributions on the $X-Y$ plane at the transducer's depth corresponding to figures 9 (a)-(f). They show that the high temperature region can be further extended to the skin when a water temperature of $41{ }^{\circ} \mathrm{C}$ is used. At a low blood perfusion case, the resulting heating pattern becomes more uniform than the high blood perfusion case.

\subsection{Whole breast heating}

The above study discusses the effects of control parameters of the proposed heating system and its feasibility to produce localized heating or uniform slice heating of a breast. For clinical use, the entire breast heating may be required. As shown in figure 5, when a large transducer is used, the high temperature region becomes irregular; hence, it is difficult to produce uniform heating of the entire breast by using a single transducer. To overcome this problem, small transducers located at different depths with separate power control can be employed. Figure 10 reveals a transient temperature response as a design example of the proposed heating system for producing uniform heating of the whole breast. The treatment object was to heat the entire breast to a temperature higher than $41{ }^{\circ} \mathrm{C}$. Six transducers with separate power control were arranged in three layers to heat the breast at different depths. To produce uniform heating from 

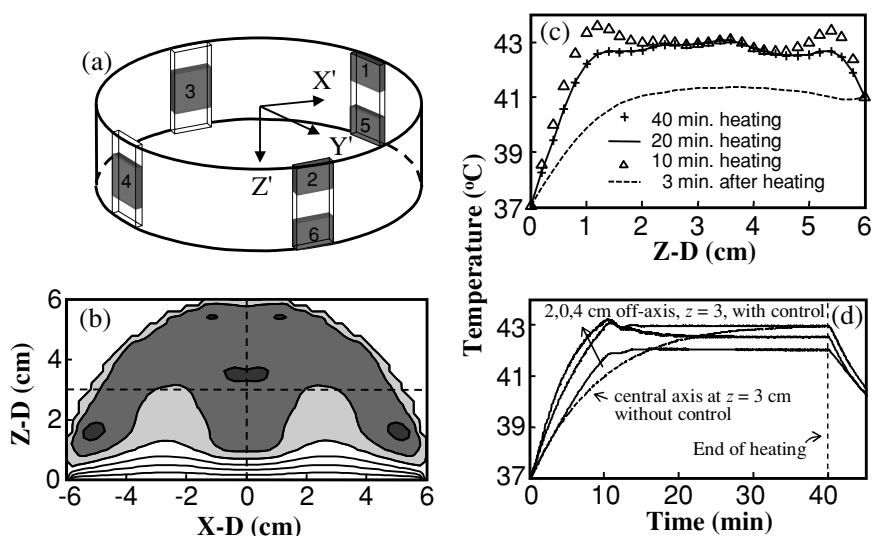

Figure 10. (a) The arrangement of transducers for producing uniform heating of the entire breast. Each track of transducers was arranged on the cylindrical supporter with $90^{\circ}$ apart. Specifications of each transducer are listed in table 3. A fuzzy logic controller was used during the heating process and the heating time was $40 \mathrm{~min}$; (b) temperature distribution after 40 min heating; (c) temperature distribution along the central axis of the breast after 10, 20, 40 min heating and 3 min after 40 min heating; (d) transient temperature response at distances of 0 (black), 2 (grey) and 4 (grey) $\mathrm{cm}$ off-axis at $Z=3 \mathrm{~cm}$; black, broken line indicates transient temperature response at $(X, Y, Z)=(0,0,3)$ for similar simulation without the fuzzy logic control.

Table 3. Specifications of transducers for producing uniform heating of breast.

\begin{tabular}{lllllc}
\hline $\begin{array}{l}\text { Exciting } \\
\text { group }\end{array}$ & $\begin{array}{l}\text { Transducer } \\
\text { no. }\end{array}$ & $\begin{array}{l}\text { Frequency } \\
(\mathrm{MHz})\end{array}$ & $\begin{array}{l}\text { Position } \\
(\text { at } Z \mathrm{~cm})\end{array}$ & $\begin{array}{l}\text { Size } \\
\left(\mathrm{cm}^{2}\right)\end{array}$ & $\begin{array}{l}\text { Power } \\
(\mathrm{W})\end{array}$ \\
\hline A & 1 & 1.08 & 1 & $3 \times 2$ & 7.8 \\
& 3 & 3.42 & 3 & $3 \times 3$ & 11.7 \\
& 5 & 1.08 & 5 & $3 \times 2$ & 0 \\
B & 2 & 3.42 & 1 & $3 \times 2$ & 13.0 \\
& 4 & 1.08 & 3 & $3 \times 3$ & 6.5 \\
& 6 & 3.42 & 5 & $3 \times 2$ & 6.5 \\
\hline
\end{tabular}

the central to the superficial portion of the breast, each layer consists of a low $(1.08 \mathrm{MHz})$ and a high (3.42 MHz) frequency ultrasound transducer. Figure 10(a) shows the arrangement of the transducers. The specifications of each transducer are listed in table 3 . To prevent serious phase interference between two ultrasound beams, these transducers were divided into two groups; group A includes transducers 1, 3 and 5, and others are group B (see table 3). Transducers in the same group were excited together for a scanning cycle, and groups A and B were excited alternatively. A scanning speed of $5 \mathrm{~s}$ per cycle was employed. In this simulation, the scanning angle was $360^{\circ}$, the shifting distance was zero, the cooling water temperature was $41{ }^{\circ} \mathrm{C}$ and the heating time was $40 \mathrm{~min}$.

Figure 10(b) is the sagittal temperature distribution after a 40 min heating. It can be seen that uniform heating of the whole breast can be obtained. Figure 10(c) plots the temperature elevations in the central axis of the breast for 10, 20 and 40 min heating and 3 min after the $40 \mathrm{~min}$ heating. Figure 10(d) shows the response of the temperature profile at 0,2 and $4 \mathrm{~cm}$ off-axis at a depth of $3 \mathrm{~cm}$. For comparison, a temperature response at $(X, Y, Z)=(0,0,3)$ without a controller is also presented. The temperature responses display vibrating shapes which indicate the temperature fluctuation when the transducer is scanned. The magnitude of the fluctuation is small. The reason could be the low blood perfusion of the breast and 
the high scanning speed of the system (Moros et al 1988). With the fuzzy logic controller, the temperature rose rapidly and a little 'overshoot' was obtained at $\sim 10 \mathrm{~s}$. The overshoot effect is also demonstrated in figure 10(c). After a 20 min heating, the temperature response approached a steady state. For the situation of heating without a controller, the temperature rose slowly and it took almost 40 min to reach the steady state.

\section{Discussion}

This paper investigates the feasibility of a scanned cylindrical ultrasound system for producing uniform heating from central to superficial portions of the breast or localized heating within the breast at a specific location. Simulation results indicate that the size of the transducer, the driving frequency, the scan angle, the shifting distance and the cooling water temperature are the control parameters for the temperature distribution. By selecting a set of appropriate parameters, a desired heating pattern can be obtained.

A deep target volume cannot be heated to a therapeutic temperature by a stationary low frequency planar ultrasound transducer. This is because ultrasound energy is exponentially attenuated along the penetration path into the breast, and overheating will occur in the intervening tissue between the skin and the target volume. To overcome this problem, the planar transducer was arranged in a cylindrical system and scanned back and forth in this study. The ultrasound energy can be overlapped in the central portion of the system. Owing to the ultrasound energy being highly overlapped in the central portion of the system, a deep, localized heating can be obtained (figures 6(a) and (b)). If the target volume is located at an off-axis region, the system can be shifted at a distance to move the overlapping zone to the target volume (figures 7(a) and (b)). The effect of moving the high temperature region by shifting the heating system is also shown in the experimental result (figure 4(a) and (c)).

To produce a superficial heating, a suitable high frequency ultrasound transducer should be used in this scanned cylindrical heating system. The ultrasound frequency needs to be high enough to have a higher attenuation effect to prevent the overheating of deep tissue. In this study, we used a $3.42 \mathrm{MHz}$ ultrasound to heat the superficial portion of the breast. Figure 6(d) shows the temperature distribution for a $3.42 \mathrm{MHz}$ transducer with a $360^{\circ}$ scanning. Unlike the low frequency ultrasound, the superficial portion was heated to a high temperature level while the temperature in the central portion was still maintained at a low level. Figures 8(b) and (e) further reveal that the high temperature region in the superficial breast can be controlled by changing the scan angle $\varphi$ to cover the desired treatment region. As the high frequency transducer moves to the tip portion of the breast, both the superficial and the central regions are heated (figure 6(c)). The reason is that less ultrasound power is attenuated for the tip portion of the breast such that more power is deposited in the overlapping zone. Hence, when a large transducer with $3.42 \mathrm{MHz}$ frequency is used, the high temperature region becomes irregular and moves to the tip portion of the breast (figure 5(f)). This effect is also shown in low frequency simulations (figures 5(a)-(c)) and the combination of low and high frequencies simulations (figure 9); the high temperature region is slightly shifted towards the tip portion of the breast rather than symmetric to the transducer's central plane, especially for a larger transducer. Hence, a smaller transducer is suggested. When the target volume is large, several transducers with separate power control can be used to cover the entire target volume.

By combining the characteristics of low and high frequency ultrasound for the proposed heating system, it is capable of producing uniform heating from the central to the superficial regions of the breast and the shape of the high temperature region can be controlled by the scan angle (figure 9). The temperature rise in the intervening region between the central and the superficial regions of the breast is contributed by two components: the ultrasound 
power deposition and the thermal conduction from both the central and superficial regions of the breast. For the bottom of the breast, the power deposition in this intervening region is small; hence, it becomes difficult to heat this region (figures 9(c) and (f)), especially when blood perfusion is high, because the power deposition and the thermal conduction are not high enough to compensate heat dissipated by blood perfusion. In order to produce uniform heating at those situations, the driving frequency of the transducer should be properly selected. On the other hand, when the blood perfusion is low, it becomes easier to heat the intervening region, and a uniform high temperature region from the central to the superficial portions of the breast can be obtained (figure $9(\mathrm{~d})$ ). This phenomenon is also shown in the phantom experiment and the non-perfused simulation (figure 4(b)). The temperature of cooling water on the breast skin can be used as a control parameter to vary the breast temperature distribution during ultrasound hyperthermia. The influence of the cooling water is about $1 \mathrm{~cm}$ deep (Moros et al 1996, Lin et al 1999), and it can be combined with the power pattern formed by the system parameters to produce a desired heating pattern close to the skin. Comparing figures 8(f) and 9(b), which have the same conditions except the temperature of cooling water, the high temperature region is closer to the skin when a higher temperature of cooling water was used.

Blood perfusion varies significantly with the heterogeneity of tissues and temperature rise. Waterman and Kramer (1994) indicate that during hyperthermia, blood flow rate may vary significantly, even in the same measurement point. In this study, a wide range of blood perfusions $\left(0.5-3.5 \mathrm{~kg} \mathrm{~m}^{-3} \mathrm{~s}^{-1}\right)$ of the breast is examined (figures $9(\mathrm{~d})-(\mathrm{f})$ ). When the blood perfusion increases, a higher power weighting of the low frequency component is required for uniform heating. These results agree with the study by Lu et al (1996). Low and high frequency components play different roles during uniform heating. The high frequency component is used to compensate the heat conducted to the cooling water; while the low frequency component is used to overcome the heat dissipated by the blood perfusion.

The above study demonstrates that

1. the ultrasound frequency $(f)$, the shifting distance $(D)$ of the system and the scan angle $(\varphi)$ of the transducer are the potential parameters for controlling the pattern of the high temperature region;

2. for superficial heating treatments, high frequency ultrasound should be used and the scan angle can be changed to obtain an appropriate high temperature region to cover the desired treatment region;

3. for deep heating treatments, low frequency ultrasound should be used and the shifting of the system can move the high temperature region;

4. the combination of low and high frequencies can result in a pretty uniform plateau of temperature rise from the superficial to the central portions of the breast and the size of the plateau can be determined by the scan angle;

5. the cooling water temperature is an additional control parameter that could be used to improve the temperature distributions for superficial heating.

According to the guideline described above, appropriate control parameters could be selected for a specific treatment. Figure 11 reveals three different planning target volumes (PTV) for the system to produce specific treatments. A converge volume index (CI) and an external volume index (EI) were used for quantitative evaluation of the treatments $(\mathrm{Ju}$ et al 2003). CI is defined as the fraction volume of the PTV elevated higher than $41{ }^{\circ} \mathrm{C}$, and EI is the ratio of the volume outside the PTV with temperature higher than $41{ }^{\circ} \mathrm{C}$ to the volume of the PTV. Figures 11(a)-(c) display the heating patterns for deep-seated, superficial or sliced target volumes, respectively. The PTV region is represented by dotted lines. The control parameters used and the resulting quantitative index are listed in table 4. 


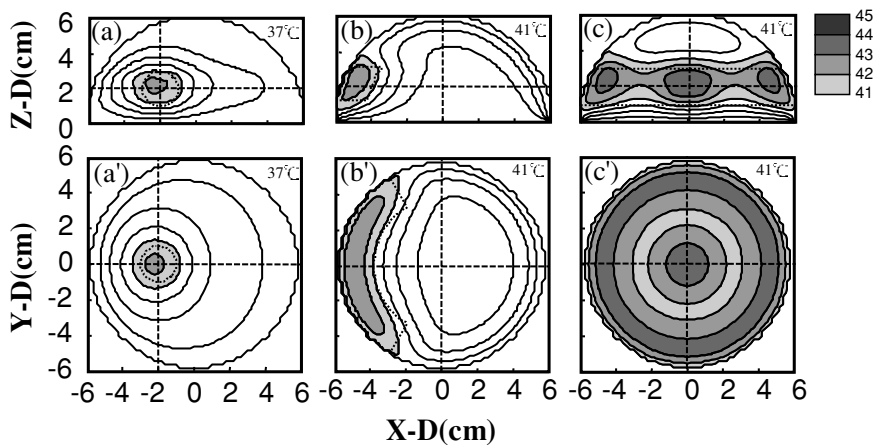

Figure 11. Temperature distribution for the treatment of (a) deep-seated sphere PTV with a diameter of $2 \mathrm{~cm}$ at $(X, Y, Z)=(-2,0,2)$; (b) superficial PTV from the skin to $2 \mathrm{~cm}$ under the skin with an angle of $120^{\circ}$ and a width of $2 \mathrm{~cm}$ located at $Z=2 \mathrm{~cm}$; (c) sliced PTV from the central to the superficial portion of the breast with a width of $2 \mathrm{~cm}$ at $Z=2 \mathrm{~cm}$. Parameters used are listed in table 4. The dotted lines represent the PTV region.

Table 4. Control parameters used for heating specific target volumes and the resulting quantitative indices.

\begin{tabular}{|c|c|c|c|c|c|c|c|c|c|}
\hline \multirow[b]{2}{*}{$\begin{array}{l}\text { PTV } \\
\text { Position, shape, size }\end{array}$} & \multicolumn{6}{|c|}{ Control parameters } & \multicolumn{3}{|c|}{ Results } \\
\hline & $\begin{array}{l}\text { Frequency } \\
(\mathrm{MHz})\end{array}$ & $\begin{array}{l}\phi \\
\left({ }^{\circ}\right)\end{array}$ & $\begin{array}{l}\text { Size } \\
(\mathrm{cm})\end{array}$ & $\begin{array}{l}D \\
(\mathrm{~cm})\end{array}$ & $\begin{array}{l}T_{\mathrm{w}} \\
\left({ }^{\circ} \mathrm{C}\right)\end{array}$ & $\begin{array}{l}\text { Power } \\
\text { (W) }\end{array}$ & $\begin{array}{l}\mathrm{CI} \\
(\%)\end{array}$ & $\begin{array}{l}\text { EI } \\
(\%)\end{array}$ & $\begin{array}{l}T_{\max } \\
\left({ }^{\circ} \mathrm{C}\right)\end{array}$ \\
\hline $\begin{array}{l}\text { Deep seated sphere with } \\
2 \mathrm{~cm} \text { diameter at } \\
(X, Y, Z)=(-2,0,2)\end{array}$ & 1.08 & 360 & $3 \times 3$ & 2 & 37 & 5.1 & 84.4 & 25.9 & 42.2 \\
\hline $\begin{array}{l}\text { Superficial from skin to } \\
2 \mathrm{~cm} \text { under skin with width } \\
2 \mathrm{~cm} \text { and angle } 120^{\circ} \text { at } \\
Z=2 \mathrm{~cm}\end{array}$ & 3.42 & 120 & $3 \times 3$ & 0 & 41 & 3.8 & 74.7 & 14.3 & 42.7 \\
\hline $\begin{array}{l}\text { Sliced form superficial to } \\
\text { central portion with width } \\
2 \mathrm{~cm} \text { at } Z=2 \mathrm{~cm}\end{array}$ & 1.08 and 3.42 & 360 & $3 \times 3$ & 0 & 41 & 6.3 and 10.0 & 86.3 & 18.9 & 43.9 \\
\hline
\end{tabular}

$T_{\mathrm{w}}$ : cooling water temperature.

$T_{\max }$ : maximum temperature in tissue.

In figure 11(a), the PTV is a sphere with a diameter of $2 \mathrm{~cm}$, located at $(X, Y, Z)=(-2,0$, 2). The PTV is deep-seated and $2 \mathrm{~cm}$ off-axis; hence, a low frequency ultrasound and a $2 \mathrm{~cm}$ shifting distance with a $360^{\circ}$ scanning were employed. The simulation result indicates that $84.4 \%$ of the PTV is heated higher than $41{ }^{\circ} \mathrm{C}$ with an overheating volume of $25.9 \%$ of the PTV in normal tissue. Figure 11(b) shows the simulation result for a PTV from the skin to $2 \mathrm{~cm}$ under the skin with a width of $2 \mathrm{~cm}$ and an angle of $120^{\circ}$ at $Z=2 \mathrm{~cm}$. Because the PTV is superficial, a high frequency ultrasound and a high cooling water temperature should be used. The scan angle of the transducer is $120^{\circ}$ and the shifting distance is zero. In figure 11(c), the PTV is a slice from the central to the superficial portion of the breast with a width of $2 \mathrm{~cm}$ at $Z=2 \mathrm{~cm}$. The target of this treatment is to produce a sliced uniform heating from the superficial to the central portion of the breast. Hence, the combination of low and high frequency ultrasound with a $360^{\circ}$ scanning and a zero shifting distance could be used. A cooling water temperature of $41{ }^{\circ} \mathrm{C}$ could also be used to improve the resulting heating pattern. 


\section{Conclusions}

This study employs the simulation study to examine the ability of a scanned cylindrical ultrasound heating system for producing uniform or localized breast hyperthermia. The system consists of high or low frequency ultrasound transducers and a mechanical scanning system. High frequency ultrasound should be used for superficial heating of the breast. Low frequency ultrasound has the ability to produce a deep-seated, localized heating within the breast. By combining the low and high frequency ultrasound, it is capable of producing uniform heating from the central to the superficial region of the breast. Non-perfused experimental results show agreement with the simulation studies.

\section{Acknowledgment}

The author would like to thank the National Science Council of Taiwan for partially supporting this research under contract no. NSC 93-2213-E-002-068.

\section{References}

Bornstein B A, Zouranjian P S, Hansen J L, Fraser S M, Gelwan L A, Teicher B A and Svensson G K 1993 Local hyperthermia, radiation therapy and chemotherapy in patients with local-regional recurrence of breast carcinoma Int. J. Radiat. Oncol. Biol. Phys. 25 79-85

Bowman H F 1982 Thermodynamics of tissue heating: modeling and measurements for temperature distributions Physics Aspect of Hyperthermia ed G H Nussbaum (New York: American Institute of Physics) pp 511-48

Chen Y Y, Lin W L, Liou H L, Yen J Y and Shieh M J 1999 Self-tuning fuzzy logic control for ultrasound hyperthermia with reference temperature based on objective functions Med. Phys. 26 825-33

Daum D R and Hynynen K 1999 A 256-element ultrasonic phased array system for the treatment of larger volumes of deep seated tissue IEEE Trans. Ultrason. Ferroelectr. Freq. Control 46 605-12

Ebbini E S and Cain C A 1991 A spherical-section ultrasound phased array applicator for deep localized hyperthermia IEEE Trans. Biomed. Eng. 38 634-43

Foster F S and Hunt J W 1979 Transmission of ultrasound beams through human tissue-focusing and attenuation studies Ultrasound Med. Biol. 5 257-68

Hynynen K and Edwards D K 1989 Temperature measurements during ultrasound hyperthermia Med.Phys. 16 618-26

Ju K C, Chen Y Y, Lin W L and Kuo T S 2003 One-dimensional phased array with mechanical motion for conformal ultrasound hyperthermia Phys. Med. Biol. 48 167-82

Kumaradas J C and Sherar M D 2003 Optimization of a beam shaping bolus for superficial microwave hyperthermia waveguide applicators using a finite element method Phys. Med. Biol. 48 1-18

Lin W L, Yen J Y, Chen Y Y, Jin K W and Shieh M J 1999 Relationship between acoustic aperture size and tumour conditions for external ultrasound hyperthermia Med. Phys. 26 818-24

Liu H L, Chen Y Y, Yeh J Y and Lin W L 2004 Pilot point temperature regulation for thermal lesion control during ultrasound thermal therapy Med.Biol. Eng. Comput. 42 178-88

Lu X Q, Burdette E C, Bornstein B A, Hansen J L and Svensson G K 1996 Design of an ultrasonic therapy system for breast cancer treatment Int. J. Hyperthermia 12 375-99

Lu X Q, Burdette E C and Svensson G K 1998 Ultrasound field calculation in a water-soft tissue medium Int. J. Hyperthermia 14 169-82

Madsen E L, Zagzebski J A, Banjavie R A and Jutila R E 1978 Tissue mimicking materials for ultrasound phantoms Med. Phys. 5 391-4

Malinen M, Huttunen T, Hynynen K and Kaipio J P 2004 Simulation study for thermal dose optimization in ultrasound surgery of the breast Med. Phys. 31 1296-307

Moros E G et al 1996 Power deposition conformability of the surlas: a system for external simultaneous thermoradiotherapy Proc. 7th Int. Cong. Hyperthermic Oncology (Rome, Italy) vol 2 pp 470-2

Moros E G, Roemer R B and Hynynen K 1988 Simulations of scanned focused ultrasound hyperthermia-the effects of scanning speed and pattern on the temperature-fluctuations at the focal depth IEEE Trans. Ultrason. Ferroelectr. Freq. Control 35 552-60

Ocheltree K B and Frizzell L A 1989 Sound field calculation for rectangular sources IEEE Trans. Ultrason. Ferroelectr. Freq. Control 36 242-7 
Overgaard J 1989 The current and potential role of hyperthermia in radiotherapy Int. J. Radiat. Oncol. Biol. Phys. 16 535-49

Pennes H H 1948 Analysis of tissue and arterial blood temperatures in the resting human forearm J. Appl. Physiol. 1 19-122

Roemer R B 1990 Thermal dosimetry Thermal Dosimetry Planning ed M Gautherie (Berlin: Springer) pp 119-214

Skinner M G, Iizuka M N and Kolios M C 1998 A theoretical comparison of energy sources-microwave, ultrasound and laser-for interstitial thermal therapy Phys. Med. Biol. 43 3535-47

van der Zee J, Gonzalez D G, van Rhoon G C, van Dijk J D P, van Putten W L J and Hart A A M 2000 Comparison of radiotherapy alone with radiotherapy plus hyperthermia in locally advanced pelvic tumours: a prospective, randomised, multicentre trial Lancet 355 1119-25

Waterman E M and Kramer D B 1994 Changes in human tumour blood flow during four weeks of hyperthermia (abstract) 14th Annual Meeting of the North American Hyperthermia Society $\mathrm{p} 125$ 